\section{The Natural History of a Gastric Tube that Was Accidentally Swallowed and Forgotten}

Medical literature is full of studies concerning bizarre foreign bodies ingested either voluntarily or involuntarily. This report describes the natural history of an accidentally swallowed 9-mm gastric tube that remained in the stomach for years without causing severe symptoms. A slim 32-year-old woman presented to our endoscopy unit with slight upper abdominal discomfort, which she had already been experiencing for years. She brought along a recent abdominal radiograph that showed a twice-folded radiopaque tubelike object $73 \mathrm{~cm}$ long and $1.3 \mathrm{~cm}$ wide in the epigastrium (Figure 1). Upper endoscopy revealed a rigid, black, folded tube in the body of the stomach, partially adherent to the mucosa (Figure 2). Despite numerous attempts, including use of the rigid esophagoscope under general anesthesia, the foreign body could not be extracied endoscopically. It was too dangerous to unfold it within the stomach because of potential injury to the gastroesophageal junction. A gastrotomy was therefore performed, and the foreign body was then easily removed. The patient has recovered well, is free of complaints, and has gained weight.

The tube was analyzed. It consisted of polyvinyl plastic. Until a decade ago, anesthetists used these for rapid gastric decompression. They also were in use for gastric lavage in emergency units. Longterm exposure to gastric juice was apparently responsible for the loss of flexibility of the tube and for the change in its color from the original transparency to black.

The patient's history was reconstructed. She vehemently denied ever having swallowed anything tube-like apart from spaghetti. At the age of 16 she had undergone cholecystectomy, and five years later had undergone gastric lavage following an overdose of benzodiazepines. It seems plausible to assume that the tube had been left in situ by mistake after one of these therapeutic procedures, and that it was subsequently swallowed by the awakening, but still unconscious, patient.

It is extremely important to ensure that objects inserted orally in unconscious individuals are not swallowed, so that complaints such as this one do not occur.

\section{Oberwalder ${ }^{4}$, M. Brugger ${ }^{2}$, R. Pointner ${ }^{2}$}

'Second Department of Surgery, University Hospital, Innsbruck, Austria;

${ }^{2}$ Department of Surgery, Krankenhaus Zell am See, Austria

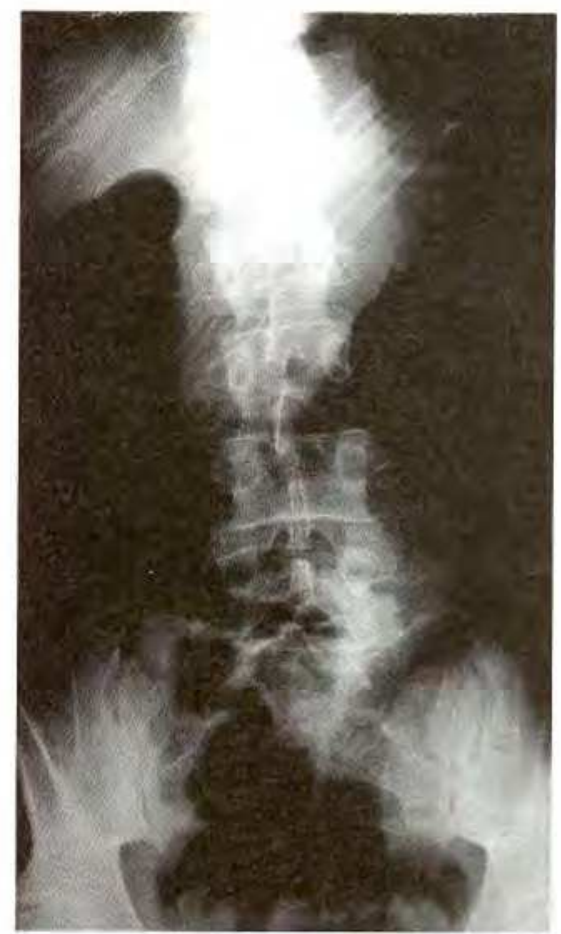

Figure 1: An abdominal radiograph showing a radiopaque, tube-like ob. ject in the epigastrium.

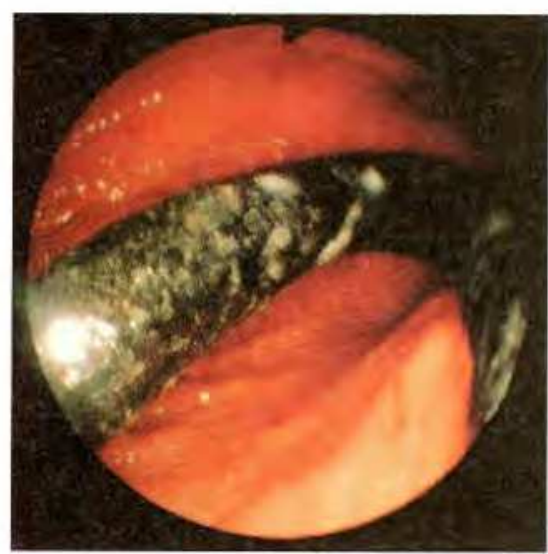

Figure 2: Upper endoscopy shows a black, folded tube in the body of the stomach.

Corresponding Author

M. Oberwalder, M.D.

Second Department of Surgery

University Hospital

Anichstrasse 35

A-6020 Innsbruck

Austria 